\title{
Implementasi Pendidikan Quran Tingkat Lanjut Bagi Santri Usia Dewasa
}

Supriyanti H. Rahayu ${ }^{1}$,Hidayatul Huda ${ }^{2}$, Joko Wahono ${ }^{3}$, Difla Nadjih ${ }^{4}$, A. Zain Sarnoto ${ }^{5^{*}}$ ${ }_{1,2,3,4}$ Universitas Cokroaminoto Yogyakarta, ${ }^{5}$ Institut PTIQ Jakarta

Penulis Koresponden, email: elbanyumasi@yahoo.co.id

\begin{abstract}
Abstrak
Peneliti bermaksud untuk mengetahui bagaimana Pendidikan al-Quran di Team Tartil AMM Yogyakarta termasuk faktor-faktor pendukung dan penghambat serta bagaimana team mengatasi penghambat Pendidikan alQuran di Team Tartil AMM Yogyakarta. Pola belajar orang dewasa dan pembaca Quran tingkat lanjut dalam pendidikan tersebut berbeda dengan para santri pelajar Quran yang masih berusia di bawahnya di tingkat permulaan atau mereka yang belajar di pesantren. Penelitian studi kasus bersifat kualitatif ini menggunakan beberapa instrument, observasi, wawancara mendalam, dan dokumentasi. Observasi dilakukan dengan mengikuti langsung proses pendidikan Syahadah Satu terhadap santri team tartil AMM Yogyakarta. Wawancara mendalam ditujukan kepada para informan, yaitu pengurus Yayasan, Ustaz, dan santri peserta pendidikan yang menjadi subyek penelitian. Untuk dokumentasi ditekankan pada data teks kurikulum Tartilil Qur'an. Semua data yang terkumpul kemudian dianalisis secara kulaitatif dengan pola berpikir induktif-deduktif. Pendidikan tingkat lanjut baca al-Quran memang memiliki problematika yang kompleks dari sisi waktu dan usia peserta meski harus dipuji dari niat dan kesungguhan mereka untuk fasih dalam pembacaannya.
\end{abstract}

Kata Kunci: Pendidikan Quran tingkat lanjut, Pola pendidikan, factor pendukung dan penghambat, pemecahan masalah.

\begin{abstract}
The researchers intends to find out how Al-Quran Education in the Yogyakarta AMM Tartil Team includes supporting and inhibiting factors as well as how the team overcomes the obstacles to Al-Quran Education in the AMM Tartil Team Yogyakarta. The learning patterns of adults and advanced readers of the Quran in this education are different from those of students of Quran who are younger than them at the beginning level or those studying in Islamic boarding schools. This qualitative case study research uses several instruments, observation, mandala interviews, and documentation. Observations were made by directly following the Syahadah One education process for the students of the AMM Yogyakarta tartil team. In-depth interviews were addressed to informants, namely the management of the Foundation, Ustaz, and students participating in the education who were the object of the research. For documentation, it is emphasized on the data of the Tartilil Qur'an curriculum text. All collected data were then analyzed in a cumulative manner with inductive-deductive thinking patterns. Advanced
\end{abstract}

This is an open access article under the (C-BY-SA license @) (1) @ 
education to read the Koran does have complex problems in terms of time and age of the participants, although it must be commended for their intention and sincerity to be fluent in reading it.

Keywords: advanced Al-Quran Education, learning pattern, supporting and inhibiting factors, overcoming

\section{Pendahuluan}

Tilawah Quran telah menjadikan kitab suci ini sebagai keharusan untuk diperlakukan sebagai kegitan pembacaan harian dalam kehidupan umat. Allah SWT pun telah mengistimewakannya sebagai ibadah bagi siapapun pembaca Quran secara sungguh-sungguh. Kenikmatannya tidak semata dihitung per ayat atau per kata, bahkan per huruf (Rauf 2011).

Qiraah ataupun pembacaan Quran melalui tilawah bukanlah tindakan yang gampang meski tidak terlalu rumit. Tuntunannya pada pemeliharaan bacaan Quran yang sama dengan saat penurunannya kepada Rasululllah saw melalui malaikat Jibril. Dalam sejarah kebangkitan Islam pun telah diterangkan bagaimana Nabi mengajarkannya dengan menunjuk beberapa sebagian sahabat setelah bacaan mereka didengar oleh beliau. Mereka inilah yang melanjutkan pengajarannya kepada generasi selanjutnya, dan demikianlah seterusnya. Quran, dengan demikian, telah diturunkan secara berkelanjutan dalam kondisi tanpa kekurangan atau tambahan dari seluruh sisi baca tulisnya.

Seiring Islam telah berkembang di luar wilayah Arab hingga berbagai belahan dunia, pembacaan Quran pun demikian. Orang tua pun telah diwajibkan untuk mengajarkan dan membiasakan bagi anak-anaknya dalam pembacaan Quran.

Didiklah anakmu dengan tiga perkara, yaitu mencintai Nabimu, mencintai keluarga Nabi, dan membaca Al-Qur'an, sesungguhnya orang yang berpegang teguh pada Al-Qur'an berada pada perlindungan Allah SWT. pada hari tidak ada perlindungan kecuali lindungan-Nya bersama-sama dengan Nabi-nabi dan Sahabat-sahabatnya yang tulus" (H.R. AdDaylami dari 'Iliyyi) (Budiyanto 2008b:2).

Permasalahan muncul ketika para qari' non-Arab mengalami kesulitan karena kendala penguasaan huruf, aksen dan cara bacanya. Sementara semua 
itu adalah bagian dari pemeliharaan Quran yang tidak bisa dikesampingkan. Mengingat keterbatasan dari jumlah orang yang menguasai baca Quran terutama dalam hal tilawah, maka ulama ahli qira'ah meletakkan kaidahkaidah cara membaca yang baik dan benar yang disebut dengan tajwid (Annuri 2016). Al-Jazari kemudian mewajibkan kepada setiap muslim berbahasa ibu Arab ataupun bukan untuk membaca sesuai dengan kaidah tajwid. Tuntunan demikian mengharuskan seorang santri pelajar untuk pertemuan secara berhadapan langsung melalui talaqqi agar diketahui langsung penguasaan tajwid dari para pembaca (Kamarul Azmi Jasmi dan Mohd Aderi Che Noh 2013).

Metode ini juga dikenal dengan sorogan dalam tradisi pendidikan Quran dalam pesantren di Indonesia (Musodiqin, Nadjih, dan Nugroho 2017; Solo, Nugroho, dan Nadjih 2018). Di kawasan ini, pembelajaran Quran telah begitu semarak dan memasyarakat. Quran telah dibiasakan sejak bayi, dikenalkan hurufnya pada masa anak usia dini (Hidayat 2017; Imroatun 2017). Jenjang selanjutnya Quran dikenalkan dalam beragam bentuk, sebagian dari mereka terlibat dalam proses hafalan melalui tahfid Quran. Tingkatan berikutnya diharapkan menjadi bagian pendidikan seumur hidup yang tertanam dalam masing-masing muslim Indonesia.

Berbagai metode pengajaran Quran telah berkembang di Indonesia. Namun kebanyakan masih didominasi penggunaannya untuk para pemula atau anak-anak. Saifullah (2017) telah membandingkan secara kuantitatif proses pembelajaran membaca al-Qur'an bermetode an-Nahdliyah dan Iqro' karena keduanya praktis dan ringan untuk pembelajaran pemula. Kesimpulannya ada perbedaan kemampuan membaca al-Qur'an bagi para satri TPA yang diteliti dengan menggunakan kedua metode tersebut. Abidin (2017) kemudian mendeskripsikan hasil penelitiannya tentang model pembelajaran al-Qur`an dilakukan dengan cara active learning bagi pemula pada sebuah pondok di Jombang. Ia menekankan keberhasilan model itu dengan menunjukkan bahwa telah banyak yang mahir membaca al-Qur'an setelah belajar nol sehingga prestasi di tingkat local kabupaten, regional propinsi termasuk nasional telah banyak diraih. Srijatun (2017) juga 
mendeskripsikan tentang implementasi metode Iqro' bagi anak Usia dini di taman kanak. Disitu ada kesimpulan bahwa pertama pembelajaran baca tulis Al-Qur'an dengan metode Iqro perlu persiapan dan perencanaan yang sistematis merujuk kepada kurikulum RA. Namun ia memberikan petunjuk penting bagi penelitian yaitu perlunya pelatihan secara rutin untuk penerapan metode Iqro bagi Guru RA.

Penelitian kualitatif dari Athoulloh dan Khambali (2018) memberikan gambaran implementasi pembelajaran Quran bagi orang dewasa melalui pembelajaran intensif. Tujuannya supaya mahasiswa yang sudah mampu membaca Al-Qur'an dapat meningkatkan kemampuan bacaannya menjadi lebih baik. Pelaksanaanya dikhususkan pada mahasiswa di pesantren UICCI Sulaimaniyah Bandung.

Semua penelitian di atas memiliki benang merah pada arti penting talaqqi dan sorogan masih menjadi pembelajaran penting dalam baca Quran di Indonesia. Walaupun demikian, kendala bahasa yang kontras dengan bahasa Indonesia masih menjadi persoalan tersendiri. Orang dewasa termasuk para pengajarnya masih membutuhkan pemahaman mendalam termasuk pembiasaan berkelanjutan dalam cara tilawah Quran yang benar. Apalagi mereka yang tidak konsentrasi penuh untuk tahsin dalam bentuk pesantren namun masih merasa perlu belajar di tingkat lanjut.

Pembelajaran tingkat lanjut atau tahsin ini kemudian bertujuan;

"1) menjaga dan memelihara kehormatan, kesucian dan kemurnian Al-Qur'an dari cara membaca yang benar, sesuai kaidah tajwid sebagaimana bacaannya Nabi Muhammad SAW.

2) Menyebarkan ilmu baca Al-Qur'an yang benar dengan cara yang benar. Agar selaras dengan tujuan di atas dapat direalisasikan secara nyata, maka metode tahsin berusaha agar dalam mengajarkan ilmu baca Al-Qur'an dengan cara yang benar sebagaimana contoh dari sunnah Rasulullah SAW. 3) Mengingatkan kepada guru-guru Al-Qur'an agar dalam mengajarkan Al-Qur'an harus berhati-hati jangan sembarangan. Membaca Al-Qur'an mempunyai kaidah tertentu agar ketika membacanya tidak mengalami kekeliruan makna yang akan berakibat dosa bagi para pembacanya, untuk itu para guru AlQur'an harus berhati-hati dalam membaca Al-Qur'an" (Annuri 2016). 
Pola belajar orang dewasa dan pembaca Quran tingkat lanjut demikian berbeda dengan mereka yang masih berusia di bawahnya atau mereka yang belajar di pesantren. Faktor-faktor yang mempengaruhi kelancaran dan keberhasilan proses pembelajaran lebih bervariasi dari pada yang lain. Team Tadarus AMM (Angkatan Muda Masjid dan Musholla) Yogyakarta adalah Bagian dari Balai Penelitian dan Pengembangan Sistem Pengajaran Baca Tulis Al-Qur'an LPTQ Nasional DI Yogyakarta (SK LPTQ Nasional Nomer 1 Tahun 1991, tertanggal 7 Pebruari 1991) (Budiyanto 2008a). Terletak di komplek masjid Baiturrahman Selokraman Purbayan Kotagede Yogyakarta. Team Tartil adalah lembaga kursus Al-Qur'an untuk menyiapkan para ustaz, da'i, imam, khatib dan sebagainya agar fasih, berkualitas dan mengetahui ilmu tajwid serta bacaan-bacaan asing atau garib (Budiyanto 2008b).

Lembaga ini mengajarkan Al-Qur'an yang diharapkan santri mampu membaca al-Qur'an dengan baik dan benar sesuai dengan kaidah ilmu tajwid. Kelompok ini berkerja di bawah Yayasan Team Tadarus AMM "As'ad Humam" Yogyakarta. Melalui Team Tartil ini, diharapkan mampu membekali para ustaz dan aktifis lainnya untuk bersama-sama meningkatkan kualitas sekaligus mampu mengajarkan kepada santri. Banyak ustaz yang merasa akan keterbatasan ilmu yang dimiliki untuk diajarkan pada santri, baik pada hafalan maupun ilmu tajwid.

Atas dasar inilah peneliti tertarik untuk mengadakan penelitian di AMM dengan maksud untuk mengetahui bagaimana Pendidikan Al-Qur'an di Team Tartil AMM Yogyakarta. Identifikasi juga ditujukan pada penggalian pada Faktor-faktor pendukung dan penghambat Pendidikan Al-Qur'an di Team Tartil AMM Yogyakarta serta bagaimana team mengatasi penghambat Pendidikan Al-Qur'an di Team Tartil AMM Yogyakarta. Yang diharapkan bahwa proses pembelajarannya konsisten dengan pola belajar berpusat pada pembelajar (Bowo 2015; Sarumaha 2016)

\section{Metode Penelitian}

Penelitian studi kasus bersifat kualitatif ini menggunakan beberapa instrument, observasi, wawancara mandala, dan dokumentasi. Observasi dilakukan dengan mengikuti langsung proses pendidikan Syahadah Satu 
terhadap santri team tartil AMM Yogyakarta. Semua kejadian di lokasi penelitian kemudian diamati dan dicatat (Mustofa 2007:56). Wawancara mendalam ditujukan kepada para informan, yaitu pengurus Yayasan, Ustaz, dan santri peserta pendidikan yang menjadi objek penelitian. Dari situ diharapkan akan temuan yang obyektif, maka caranya dilakukan secara langsung berhadapan dengan yang diwawancarai tetapi dapat pula secara tidak langsung seperti memberikan daftar pertanyaan untuk dijawab pada kesempatan lain (Mustofa 2007:57). Untuk dokumentasi ditekankan pada penelitian data kurikulum Kursus Tartilil Qur'an. Data ini sama dengan catatan, transkrip, buku, surat kabar, majalah, prasasti, notulen rapat, lengger, agenda dan sebagainya (Arikunto 2017:206). Semua data yang terkumpul kemudian dianalisis secara kulaitatif dengan pola berpikir induktif-deduktif.

\section{Hasil}

Team Tartil merupakan bagian dari program M5A (Membaca, Menulis, Memahami, Mengamalkan, dan Memasyarakatkan Al-Qur'an) melalui Kursus tartilil Quran. Adapun gerakan M5A tersebut diantaranya: Majelis Ta'lim dan Tadarus Al-Qur'an sejak tahun 1983; Taman Kanak- kanak AlQur'an dan Taman Pendidikan Al-Qur'an, masing-masing mulai tahun 1988 dan 1989; tahun 1991 dikembangkan Taman Kanak- kanak Al-Qur'an Lanjutan dan Taman Pendidikan Al-Qur'an lanjutan; Ta'limul Qur'an Lil Aulad terselenggara pada tahun 1990; tingkat selanjutnya adalah pendidikan kilat (diklat) ustaz di 1989; kursus Tartilil Qur'an tahun 1991; Keterpaduan BKB TKA/TPA sejak 1992; 1994 berdiri Iqro' Klasikal di Sekolah Formal; tingkat terakhir berupa Kursus Seni Baca Al-Qur'an yang dibuka mulai tahun 2003 (Budiyanto 2008b).

Program Kursus Tartilil Qur'an di AMM Yogyakarta bagi usia dewasa yang dikelola team Tartil terdiri dari syahadah 1 (S1), syahadah 2A/B (S2 A/B) dan S3. Pada tingkat akhir, pseserta diharapakan telah fasih dalam membaca Al-Qur'an, sehingga waktu ujian ia benar-benar sudah mampu menempuh ujian tanpa harus mengulangi di lain hari.

Adapun yang menjadi materi pokok tahsinul qur'an adalah pembelajaran/ pendidikan membaca Al-Qur'an dengan metode Iqro, yang 
mana iqro' sendiri dicetuskan oleh team tadarus AMM yang disusun langsung oleh pendiri AMM yakni KH. As'ad Humam. Hingga saat ini iqro' masih menjadi kebanggaan di Team Tadarus AMM, yang sudah menasional bahkan sampai kepada Negeri tetangga.

Metode iqro' adalah suatu metode membaca Al-Qur'an yang menekankan langsung pada latihan membaca. Adapun buku panduan iqro' terdiri dari 6 jilid di mulai dari tingkat yang sederhana, tahap demi tahap sampai pada tingkatan yang sempurna.Buku Iqro' yang kemudian di tengah masyarakat dikenal dengan istilah Metode Iqro' ini disusun ringkas dalam buku-buku kecil dan terbagi dalam enam jilid. Jilid-jilid tersebut disusun berdasarkan urutan dan tertib materi yang harus dilalui secara bertahap oleh masing-masing anak, sehinggga jilid 2 adalah kelanjutan jilid 1. Jilid 3 adalah kelanjutan jilid 2, demikian seterusnya sampai selesai jilid 6 (Humam 2000).

Pada edisi revisi awal tahun 2000, buku wajib itu telah lengkap dengan juz amma dengan penjelasan bagaimana pengajaran di tiap jilid. Di akhir tahun terjadi perubahan kembali dengan mengurangi juz 'amma tetapi tetap diikuti dengan petunjuk pembelajaran.

Dari sini bisa dilihat bahwa tidak perbedaan dengan tingkat pemula dalam buku pegangan. Penelitian terdahulu yang meneliti metode iqro juga menggunakan buku yang sama sebagai pembelajaran (Srijatun 2017; Syaifullah 2017). Namun ternyata ada tambahan program yang harus diikuti oleh para peserta tartil. Adapun yang menjadi materi penunjang adalah santri mampu menghafal dengan fasih materi - materi S1, S2 A / B ataupun S3. Untuk S1 adalah; Membaca Al-Qur'an secara tartil (ujian tadarus); Hafal dengan baik bacaan sholat, azan dan Iqomah, doa Ifitah, Surat Alfatihah, Do'a Ruku', sujud, Iktidal, duduk antara dua sujud, doa Tasyahud, doa setelah salat dan Azan Iqamah. Peserta program S1 juga diberi materi tentnang Hafalan 14 doa sehari-hari, antara lain; doa kelancaran bicara, doa akan belajar, doa memperoleh rahmat, doa Kebaikan dunia akhirat, doa untuk kedua orang tua, senandung Quran, doa akan dan bangun tidur, doa akan dan setelah makan, doa masuk dan keluar rumah, doa masuk dan keluar kamar kecil, doa saat mendengar azan, doa setelah azan, doa selesai wudu, doa masuk dan keluar masjid. Selanjutnya mereka juga dibekali dengan hafalan 14 surat pendek yang bermanfaat dalam salat, yaitu; An-nas, al-Falaq, 
Al-Ikhlas, Al-lahab, An-Nashr, Al-Kafirun, Al-Kautsar, Al-Ma'un, Quraisy, Al-fill, Al-Humazah, Al-'Asr, At-Takatsur, Al-Qari'ah

Metode yang digunakan fokus pada Iqro' yang memiliki beberapa kunci sukses. Santri peserta adalah pembelajar mandiri yang aktif dengan mengandalkan metode talaqqi atau sorogan dimana ustaz mendengarkan tanpa penuntunan yang ketat. Pemberian contoh pembacaan dengan praktis tanpa penjelasan lebih jauh. Ustaz juga harus memiliki kemampuan komunikasi yang memadai. Kunci sukses terakhir adalah latihan berkelanjutan dimana santri berlatih terus menerus agar terbiasa membaca Quran secara benar dan cepat (Rustiawan 2013).

Adapun metode dalam pengajaran digunakan di Yayasan Team Tartil AMM Yogyakarta. Yang utama adalah ceramah dimana penyajian informasi secara lisan, baik yang formal dan berlangsung selama 45 menit maupun yang informal dan hanya memakan waktu 5 menit (Rustiawan 2013). Metode ini digunakan dalam pendahuluan proses belajar mengajar,

ustaz dapat mengantarkan gambaran umum tentang topik itu dengan berceramah. Ketika Tidak ada sumber bahan pelajaran pada santri, sehingga santri dituntut membuat catatan-catatan penting dari bahan pelajaran yang disampaikan oleh ustaz. Ia sedang menghadapi jumlah santri yang cukup banyak, sehingga tidak memungkinkan ustaz untuk memperhatikan pelajar secara individual. Ustaz ingin membangkitkan semangat belajar pada santri. Proses belajar memerlukan penjelasan secara lisan (Rustiawan 2013).

Tanya Jawab menjadi metode yang penting seperti dalam pembelajaran yang lain sehingga memberikan dampak pada belajar (Hermawan 2016). Diskusi digunakan bergantian dipilih untuk komunikasi langsung antara ustaz dan santri. Keduanya memberikan jalan bagai pendalaman dan perluasan variasi praktik membaca Quran yang diperlukan oleh para santri (Rustiawan 2013).

Tugas belajar dan resitasi yakni tugas santri yang harus dikerjakan oleh santri biasa diistilahkan dengan pekerjaan rumah. Pertanggungjawaban santri terhadap tugas tersebut disebut resitasi (Rustiawan 2013). Metode ini dilaksanakan dengan penugasan santri untuk belajar materi yang telah di 
dapat dan materi selanjutnya, dengan tujuan pertemuan berikutnya santri tersebut lancar mengaji tanpa harus mengulang-ulang.

Metode latihan digunakan untuk memperoleh suatu ketangkasan atau keterampilan dari apa yang telah dipelajari (Rustiawan 2013). Metode ini dilakukan pada bacaan-bacaan yang di rasa cukup sulit, sehingga perlu pengulangan, dengan tujuan santri fasih pada bacaan-bacaan tersebut. Cara yang sama ditemukan dalam penelitian dalam pembelajaran tahsin untuk mahasiswa (Athoulloh dan Khambali 2018). Di satu sesi, ustaz menugaskan santrinya untuk hafal surat-surat pendek dan surat pilihan yang panjang seperti surat Yasin. Namun di Tartil dicukupkan pada surat-pendek. Selama sorogan hafalan di hadapan Ustadz sambil diperbaiki bacaan santri baik dari segi segala sisi bacaan.

Bentuk evaluasi di Yayasan Team Tadarus AMM Yogyakarta di laksanakan berdasarkan ujian langsung menghadap penguji dengan materi hafalan sebagaimana yang telah disebutkan diatas. Adapun materi tartil alQur'an (bi an-nadar) diujikan dengan materi sesuai keinginan penguji tanpa diberitahukan sebelumnya, karena hal ini menguji kelancaran dan kestabilan santri dalam membaca al-Qur'an sesuai dengan kaidah ilmu tajwid dengan benar. Evaluasi demikian diberlakukan evaluasi bagi yang menempuh program S1, S2 A/B, S3. Adapun evaluasi untuk kenaikan jilid diserahkan pada ustaz yang saat itu mengajar. kriteria penilaian evaluasi dapat dilihat pada table dibawah ini :

Tabel 1

Kriteria Penilaian Bacaan Al-Qur'an \& Hafalan Do'a - Do'a

\begin{tabular}{|c|c|c|c|c|}
\hline $\mathrm{NO}$ & $\begin{array}{l}\text { Secara } \\
\text { umum }\end{array}$ & $\begin{array}{l}\text { Nilai } \\
\text { Huruf }\end{array}$ & $\begin{array}{l}\text { Nilai } \\
\text { angka }\end{array}$ & $\begin{array}{c}\text { Keterangan } \\
\text { kategori bacaan }\end{array}$ \\
\hline 1. & \multirow{10}{*}{ 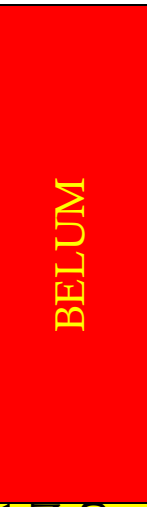 } & \multirow{10}{*}{ C- } & 55 & \multirow{10}{*}{$\begin{array}{l}\text { Masih sering } \\
\text { melakukan } \\
\text { kesalahan baca : } \\
\text { Mad, salah huruf, } \\
\text { tanda baca, } \\
\text { tasydid, waqof }\end{array}$} \\
\hline 2. & & & 55,5 & \\
\hline 3. & & & 56 & \\
\hline 4. & & & 56,5 & \\
\hline 5. & & & 57 & \\
\hline 6. & & & 57,5 & \\
\hline 7. & & & 58 & \\
\hline 8. & & & 58,5 & \\
\hline 9. & & & 59 & \\
\hline 10. & & & 59,5 & \\
\hline 11. & $Z A<$ & C & 60 & \\
\hline
\end{tabular}




\begin{tabular}{|c|c|c|c|c|}
\hline 12. & & & 60,5 & \multirow{9}{*}{$\begin{array}{c}\text { Bacaan relatif } \\
\text { baik. Kesalahan } \\
\text { baca sesekali } \\
\text { dilakukan. } \\
\text { Dengung belum } \\
\text { stabil }\end{array}$} \\
\hline 13. & & & 61 & \\
\hline 14. & & & 61,5 & \\
\hline 15. & & & 62 & \\
\hline 16. & & & 62,5 & \\
\hline 17. & & & 63 & \\
\hline 18. & & & 63,5 & \\
\hline 19. & & & 64 & \\
\hline 20. & & & 64,5 & \\
\hline 21. & \multirow{10}{*}{ 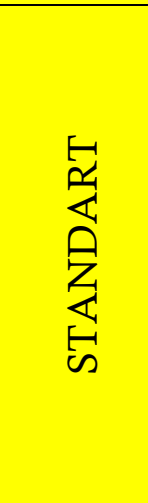 } & \multirow{10}{*}{$\mathrm{C}+$} & 65 & \multirow{10}{*}{$\begin{array}{c}\text { Tajwid terutama } \\
\text { dengung relatif } \\
\text { baik }\end{array}$} \\
\hline 22. & & & 65,5 & \\
\hline 23. & & & 66 & \\
\hline 24. & & & 66,5 & \\
\hline 25. & & & 67 & \\
\hline 26. & & & 67,5 & \\
\hline 27. & & & 68 & \\
\hline 28. & & & 68,5 & \\
\hline 29. & & & 69 & \\
\hline 30. & & & 69,5 & \\
\hline NO & $\begin{array}{l}\text { Secara } \\
\text { umum }\end{array}$ & $\begin{array}{l}\text { Nilai } \\
\text { Huruf }\end{array}$ & $\begin{array}{l}\text { Nilai } \\
\text { angka }\end{array}$ & $\begin{array}{c}\text { Keterangan } \\
\text { kategori bacaan }\end{array}$ \\
\hline 1. & \multirow{25}{*}{ 曷 } & \multirow{10}{*}{ B- } & 70 & \multirow{10}{*}{$\begin{array}{l}\text { Tajwid mulai } \\
\text { stabil. Bacaan } \\
\text { lancar }\end{array}$} \\
\hline 2. & & & 70,5 & \\
\hline 3. & & & 71 & \\
\hline 4. & & & 71,5 & \\
\hline 5. & & & 72 & \\
\hline 6. & & & 72,5 & \\
\hline 7. & & & 73 & \\
\hline 8. & & & 73,5 & \\
\hline 9. & & & 74 & \\
\hline 10. & & & 74,5 & \\
\hline 11. & & \multirow{10}{*}{ B } & 75 & \multirow{10}{*}{$\begin{array}{l}\text { Tajwid cukup } \\
\text { stabil. Fashohah } \\
\text { dan irama stabil } \\
\text { (diperkirakan } \\
\text { tidak mengaji } \\
\text { selama } 3 \text { bulan } \\
\text { berturut-turut tidak } \\
\text { menurun/berubah } \\
\text { kualitasnya) }\end{array}$} \\
\hline 12. & & & 75,5 & \\
\hline 13. & & & 76 & \\
\hline 14. & & & 76,5 & \\
\hline 15. & & & 77 & \\
\hline 16. & & & 77,5 & \\
\hline 17. & & & 78 & \\
\hline 18. & & & 78,5 & \\
\hline 19. & & & 79 & \\
\hline 20. & & & 79,5 & \\
\hline 21. & & \multirow{5}{*}{$\mathrm{B}+$} & 80 & \multirow[b]{5}{*}{ Penguasaan } \\
\hline 22. & & & 80,5 & \\
\hline 23. & & & 81 & \\
\hline 24. & & & 81,5 & \\
\hline 25. & & & 82 & \\
\hline
\end{tabular}




\begin{tabular}{|c|c|c|c|c|}
\hline \multirow{2}{*}{$\frac{26 .}{27 .}$} & & & 82,5 & \multirow{5}{*}{$\begin{array}{l}\text { tajwid, fashohah } \\
\text { dan irama sudah } \\
\text { stabil }\end{array}$} \\
\hline & & & 83 & \\
\hline 28. & & & 83,5 & \\
\hline 29. & & & 84 & \\
\hline 30. & & & 84,5 & \\
\hline NO & $\begin{array}{l}\text { Secara } \\
\text { umum }\end{array}$ & $\begin{array}{l}\text { Nilai } \\
\text { Huruf }\end{array}$ & $\begin{array}{l}\text { Nilai } \\
\text { angka }\end{array}$ & $\begin{array}{c}\text { Keterangan } \\
\text { kategori bacaan }\end{array}$ \\
\hline 1 & \multirow{30}{*}{ 是 } & \multirow{10}{*}{ B- } & 70 & \multirow{10}{*}{$\begin{array}{l}\text { Tajwid mulai } \\
\text { stabil. Bacaan } \\
\text { lancar }\end{array}$} \\
\hline 2. & & & 70,5 & \\
\hline 3. & & & 71 & \\
\hline 4. & & & 71,5 & \\
\hline 5. & & & 72 & \\
\hline 6. & & & 72,5 & \\
\hline 7. & & & 73 & \\
\hline 8. & & & 73,5 & \\
\hline 9. & & & 74 & \\
\hline 10. & & & 74,5 & \\
\hline 11. & & \multirow{10}{*}{ B } & 75 & \multirow{10}{*}{$\begin{array}{l}\text { Tajwid cukup } \\
\text { stabil. Fashohah } \\
\text { dan irama stabil } \\
\text { (diperkirakan } \\
\text { tidak mengaji } \\
\text { selama } 3 \text { bulan } \\
\text { berturut-turut tidak } \\
\text { menurun/berubah } \\
\text { kualitasnya) }\end{array}$} \\
\hline 12. & & & 75,5 & \\
\hline 13. & & & 76 & \\
\hline 14. & & & 76,5 & \\
\hline 15. & & & 77 & \\
\hline 16. & & & 77,5 & \\
\hline 17. & & & 78 & \\
\hline 18. & & & 78,5 & \\
\hline 19. & & & 79 & \\
\hline 20. & & & 79,5 & \\
\hline 21. & & \multirow{10}{*}{ B+ } & 80 & \multirow{10}{*}{$\begin{array}{c}\text { Penguasaan } \\
\text { tajwid, fashohah } \\
\text { dan irama sudah } \\
\text { stabil }\end{array}$} \\
\hline 22. & & & 80,5 & \\
\hline 23. & & & 81 & \\
\hline 24. & & & 81,5 & \\
\hline 25. & & & 82 & \\
\hline 26. & & & 82,5 & \\
\hline 27. & & & 83 & \\
\hline 28. & & & 83,5 & \\
\hline 29. & & & 84 & \\
\hline 30. & & & 84,5 & \\
\hline
\end{tabular}

Pendidikan Al-Qur'an di Team tartil pada kelas reguler di tempuh selama 20 pertemuan dengan batas maksimal 3 bulan. Tiap santri di bebaskan memilih waktu antara pagi pukul 06.00-07.30, sore pada pukul 16.00-17.30 atau berangkat 2 kali pagi dan sore. Setiap kali masuk santri dibina dengan sistem privat selama 15-20 menit. lama pendidikan di tempuh selama 20 pertemuan dengan waktu maksimal 3 bulan. Pada pertemuan perdana, 
diadakan test penjajakan kemampuan santri untuk selanjutnya mengikuti tahsinul Quran sesuai dengan kemampuan masing-masing. Penjajakan dilakukan dikarenakan kemampuan santri yang berbeda-beda. Adakalanya santri sudah mahir dengan bacaan Quran, adakalanya masih terbata-bata atau justru belum tahu sama sekali. Untuk itu, perlu diadakan penjajakan demi efektifitas waktu dan tidak salah sasaran.

Pada lembar penjajagan tersebut, kolom pertama, berisikan tentang penguasaan Makharij al-huruf sama halnya yang terdapat pada jilid I di Iqro'. Target yang ingin dicapai pada jilid I ini adalah Santri mampu membaca dan mengucapkan secara fasih makharij al-huruf secara tunggal berharakat fathah tanpa harus mengeja melainkan dibaca apa adanya. Bukan alif, ba', ta' dan seterusnya. Mereka juga mampu mampu membedakan bunyi huruf yang memiliki makhraj yang berdekatan, seperti :

Tabel 2

Huruf Hijaiyyah

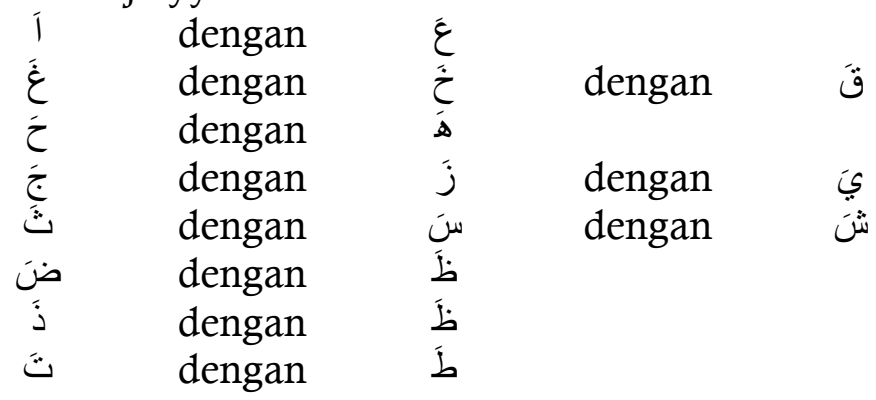

Pada kolom kedua, santri diujikan dengan materi Iqro' jilid II yang berisikan tentang huruf-huruf tunggal, huruf sambung di awal, di tengah, di belakang yang berharokat fathah. Pada kolom ketiga, santri diujikan dengan materi Iqro' jilid III yang berisikan tentang harokat selain fathah, yakni kasroh, dlommah, sukun.

Target yang ingin dicapai dalam Iqro' III adalah pengenalan bacaan kasrah, kasrah panjang diikuti huruf ya' sukun, dan kasrah panjang karena berdiri. Pengenalan bacaan dammah, dammah panjang karena diikuti wawu sukun, dan dammah panjang karena terbalik. Mengenal tanda baca fathah, kasrah, dammah dan sukun. Pengenalan huruf alif, ya' dan wawu.

Pada kolom keempat, santri diujikan dengan materi Iqro' jilid IV yang berisikan tentang bacaan fathah tanwin, kasrah tanwin dan dammah tanwin. 
Bunyi ya' sukun dan awu sukun setelah harakat fathah, nun sukun, mim sukun, qalqalah dan huruf lainnya yang berharakat sukun. Target dalam jilid IV ini adalah baru memperkenalkan bacaan idzhar belum pada bacaan idghom, ikhfa dan iqlab.

Pada kolom kelima, santri diujikan dengan materi Iqro' jilid V. materinya terdiri dari Alif lam qamariyyah, cara baca akhir ayat atau tanda waqf; cara baca mad far'; cara baca alif lam syamsiyah; cara baca nun sukun / tanwin bertemu huruf-furuf idghom bighunnah; cara baca lam jalalah; cara baca nun sukun / tanwin bertemu huruf-huruf idghom bilaghunnah. Pada kolom keenam, berisikan materi Iqro' jilid VI yang berisikan hampir semua persoalan-persoalan tajwid. Diantaranya; cara baca Idgam bigunnah, cara baca Iqlab, cara baca Ikhfa', cara baca tanda-tanda waqf dan cara baca fawatikh as-suwar.

Prinsip pengajaran Iqro' adalah praktek langsung membaca tanpa dieja. Kepada santri belum diperkenankan istilah-istilah atau teori tajwid, yang terpenting adalah santri mampu membaca Al-Qur'an dengan baik sesuai dengan kaidah tajwid meskipun belum mengenal istilah-istilah dalam ilmunya. Santri diperkenalkan teori ilmu tajwid setelah santri lulus Iqro’ juz 1-6 dan telah lancar membaca Al-Qur'an (Budiyanto 1995).

\section{Pembahasan}

Pendidikan Al-Qur'an tingkat Lanjut di Team Tadarus AMM Yogyakarta di temukan beberapa fakor pendukung. Semangat santri yang sangat baik. Hal ini memudahkan jalannya pendidikan Al-Qur'an di Yayasan Team Tadarus AMM Yogyakarta. Lokasi yang sangat strategis. AMM mudah dijangkau baik dari kabupaten Bantul, Sleman ataupun kota Yogyakarta. Administrasi yang baik dan infaq yang relatif terjangkau (Rp. 150.000 ,- per-20 pertemuan), sehingga banyak santri yang perpanjang masa belajarnya setelah habis masa 20 kali pertemuan untuk memperdalam keilmuannya khususnya ilmu di bidang membaca Al-Qur'an.

Faktor-faktor penghambat diantaranya, Santri yang sudah lanjut usia, ketika diajarkan di lain hari sudah lupa dan harus mengulangnya lagi dipertemuan berikutnya. Santri yang belajar dari kecil sudah salah, untuk 
dibetulkan membutuhkan waktu yang cukup lama. Santri sebagian besar adalah pekerja dan mahasiswa, sehingga keaktifan santri kurang, hal ini menyebabkan target 20 kali dalam 3 bulan kurang tercapai dan kemampuan santri dalam membaca terkadang menurun karena dirumah jarang dipelajarai. ustaz pengajar di team tartil baru tersedia pengajar laki-laki, sehingga ketika ada santri putri meminta ustazah belum bisa terpenuhi.

Beberapa upaya telah dilakukan untuk mengatasi factor-faktor yang menghambat dalam pendidikan Al-Qur'an di Team Tadarus AMM "As'ad Humam" Yogyakarta. Diantaranya. Sosialisasi berkelanjutan agar semua santri untuk berperan aktif, baik ketika belajar di AMM maupun belajar di rumah, sehingga pertemuan berikutnya tidak memakan waktu mengulang materi hari lalu. Upaya kedua Pembetulan kesalahan santri yang sudah menahun, dianjurkan untuk terus berlatih di rumah dengan materi yang benar yang sudah didapat di AMM, dengan cara mengulang-ulang ataupun mendengarkan kaset atau rekaman dari ustaz pengajarnya. Upaya lain telah diusahakan bagi santri yang kurang aktif, diharapkan tetap aktif belajar di rumah, dengan tujuan ilmu yang sudah diperoleh tidak lupa dan mampu berkembang. Yang terakhir Bagi santri yang menghendaki pengajar putri, biasanya diambilkan dari unit TQA yang masih bernaung di bawah lembaga AMM Yogyakarta.

\section{Penutup}

Pendidikan tingkat lanjut baca Quran memang memiliki problematika yang kompleks dari sisi waktu dan usia peserta meski harus dipuji dari niat dan kesungguhan mereka untuk fasih dalam pembacaannya. Untuk itu, ustaz diharapkan selalu memotivasi santri untuk belajar aktif di rumah. Adanya ustazah yang ditempatkan di unit team tartil. Bagi ustaz pengajar, terus berinovasi dan mengembangkan diri agar santri tidak jenuh. Bagi lembaga / yayasan, santri ada baiknya ditentukan pilihan jam masuk, sehingga ada kategori santri pagi sendiri, santri sore sendiri. Dengan demikian dapat meminimalisir banyaknya santri yang kurang terdeteksi, padahal jumlah ustaz yang bertugas terbatas. Selanjutnya santri juga tidak melupakan kewajiban 
terus berlatih dan belajar selain di AMM dengan harapan ilmu yang diperoleh dapat berkembang dan bermanfaat.

\section{Daftar Pustaka}

Abidin, Zainal. 2017. "Model Pembelajaran Al-Qur'an Bagi Pemula (Studi Kasus di Pondok Pesantren Al-Azhar Peterongan Jombang)." Sumbula: Jurnal Studi Keagamaan, Sosial dan Budaya 2(1):377-401.

Annuri, Ahmad. 2016. Panduan Tahsin Tilawah Al-Qur'an dan Tajwid. Jakarta: Pustaka Al- Kautsar.

Arikunto, Suharsimi. 2017. Prosedur Penelitian Suatu Pendekatan Praktik. Jakarta: Rineka Cipta.

Athoulloh, Abdul Fatah, dan Khambali Khambali. 2018. "Pengelolaan Pembelajaran Intensif Al-Qur'an untuk Meningkatkan Kemampuan Membaca Al-Qur'an Mahasiswa." Ta'dib: Jurnal Pendidikan Islam 7(2):539-57. doi: 10.29313/tjpi.v7i2.4443.

Bowo, Ahmad Nasir Ari. 2015. Cerita Cinta Belajar Mengajar. Yogyakarta: Deepublish.

Budiyanto, H. M. 1995. Prinsip-prinsip Metodologi Buku IQRO'. Yogyakarta: Balai Litbang LPTQ Nasional Team Tadarus "AMM."

Budiyanto, Mangun. 2008a. Paduan Praktis Pengelolaan TKA-TPA, TKAL$T P A L$, dan TQA. Yogyakarta: Balai Litbang LPTQ Nasional Team Tadarus "AMM."

Budiyanto, Mangun. 2008b. Ringkasan Pedoman Pengelolaan, Pembinaan dan Pengembangan Gerakan Membaca, Menulis, Memahami, Mengamalkan dan Memasyarakatkan Al-Qur'an (Gerakan M5A). Yogyakarta: Balai Litbang LPTQ Nasional Team Tadarus "AMM."

Hermawan, Toto. 2016. "Pengaruh Kemampuan Bertanya Terhadap Hasil Belajar." Intersections 1(1).

Hidayat, Fattah. 2017. "Kajian Psikologi Pembelajaran Hafal Quran bagi Anak Usia Dini." Proceedings of The 2nd Annual Conference on Islamic Early Childhood Education 3:83-94.

Humam, Asad. 2000. Buku Iqra, Cara Cepat Belajar Membaca Al-Qur"an, Jilid. I6. Yogyakarta: Balai Litbang LPTQ Nasional Team Tadarus "AMM."

Imroatun, Imroatun. 2017. "Pembelajaran Huruf Hijaiyah bagi Anak Usia Dini." Hal. 175-88 in Proceedings of The 2nd Annual Conference on Islamic Early Childhood Education. Yogyakarta: Program Studi Pendidikan Islam Anak Usia Dini Fakultas Ilmu Tarbiyah dan Keguruan UIN Sunan Kalijaga Yogyakarta'.

Kamarul Azmi Jasmi, dan Mohd Aderi Che Noh. 2013. Sejarah, Kaedah, Serta Model Pengajaran Dan Pembelaja-Ran Al-Quran.

Musodiqin, Muhammad, Difla Nadjih, dan Taufik Nugroho. 2017. "Implementasi Sorogan Dalam Pembelajaran Al-Qur'an Pada Madrasah Diniyah Takmiliyah." Ulumuddin: Jurnal Ilmu-ilmu Keislaman 7(1):59-71.

Mustofa, Bisri. 2007. Tuntunan Karya Ilmiah. Yogyakarta: Panji Pustaka.

Rauf, Abdul Aziz Abdur. 2011. Pedoman Dauroh Al-Qur'an. Jakarta. Markaz Al-Qur'an. 
Rustiawan, Iwan. 2013. "Metodologi Iqro'." in workshop baca al-Quran metode Iqro.

Sarumaha, Yenny Anggreini. 2016. "Perubahan Pembelajaran Yang Berpusat Pada Guru Ke Berpusat Pada Siswa." Intersections 1(1).

Solo, Ahlan Abdullah, Taufik Nugroho, dan Difla Nadjih. 2018. "Upaya Santri Dalam Pemeliharaan Hafal Al- Qur'an Di MANU Kota Gede Yogyakarta." Ulumuddin: Jurnal Ilmu-ilmu Keislaman 8(2):131-40.

Srijatun, Srijatun. 2017. "Implementasi Pembelajaran Baca Tulis Al Quran Dengan Metode Iqra Pada Anak Usia Dini Di RA Perwanida Slawi Kabupaten Tegal." Nadwa 11(1):25. doi: 10.21580/nw.2017.11.1.1321.

Syaifullah, Muhammad. 2017. "Penerapan Metode An-Nahdliyah dan Metode Iqro dalam Kemampuan Membaca Al-Qur'an." Kajian Ilmu Pendidikan 2(1):131-62. 